\title{
Ethnic differences in respiratory impairment
}

\author{
Carlos A Vaz Fragoso, ${ }^{1,2}$ Gail McAvay, ${ }^{2}$ Thomas M Gill, ${ }^{2}$ John Concato, ${ }^{1,2}$ Philip \\ $\mathrm{H}$ Quanjer, ${ }^{3}$ Peter $\mathrm{H}$ Van Ness ${ }^{2}$
}

- Additional material is published online only. To view please visit the journal online (http://dx.doi.org/10.1136/ thoraxjnl-2013-203631).

${ }^{1}$ Veterans Affairs Clinical Epidemiology Research Center, VA Connecticut Healthcare System, West Haven,

Connecticut, USA

${ }^{2}$ Department of Internal Medicine, Yale University School of Medicine, New Haven, Connecticut, USA ${ }^{3}$ Department of Pulmonary Diseases, Sophia Children's Hospital, Erasmus Medical Centre, Erasmus University, Rotterdam, The Netherlands

\section{Correspondence to} Dr Carlos A Vaz Fragoso, Veterans Affairs Clinical Epidemiology Research Center, VA Connecticut Healthcare System, 950 Campbell Ave, Mailcode 151B, West Haven, CT 06516, USA; carlos.fragoso@yale.edu

Received 26 March 2013 Revised 27 June 2013 Accepted 25 July 2013 Published Online First 12 August 2013

\footnotetext{
To cite: Vaz Fragoso CA, McAvay G, Gill TM, et al. Thorax 2014;69:55-62.
}

\begin{abstract}
Objective Spirometric Z scores by lambda-mu-sigma

(LMS) rigorously account for age-related changes in lung function. Recently, the Global Lung Function Initiative (GLI) expanded LMS spirometric Z scores to multiple ethnicities. Hence, in aging populations, the GLI provides an opportunity to rigorously evaluate ethnic differences in respiratory impairment, including airflow limitation and restrictive pattern.

Methods Using data from the Third National Health and Nutrition Examination Survey, including participants aged 40-80, we evaluated ethnic differences in GLI-defined respiratory impairment, including prevalence and associations with mortality and respiratory symptoms.

Results Among 3506 white Americans, 1860 African Americans and 1749 Mexican Americans, the prevalence of airflow limitation was $15.1 \%(13.9 \%$ to $16.4 \%)$, $12.4 \%(10.7 \%$ to $14.0 \%)$ and $8.2 \%(6.7 \%$ to $9.8 \%)$, and restrictive pattern was $5.6 \%$ (4.6\% to $6.5 \%), 8.0 \%$ $(6.9 \%$ to $9.0 \%)$ and $5.7 \%(4.5 \%$ to $6.9 \%)$, respectively. Airflow limitation was associated with mortality in white Americans, African Americans and Mexican Americansadjusted HR (aHR) 1.66 (1.23 to 2.25), 1.60 (1.09 to 2.36 ) and 1.80 (1.17 to 2.76 ), respectively, but associated with respiratory symptoms only in white Americans-adjusted OR (aOR) 2.15 (1.70 to 2.73). Restrictive pattern was associated with mortality but only in white Americans and African Americans-aHR 2.56 (1.84 to 3.55) and 3.23 (2.06 to 5.05), and associated

\section{Key messages}

What is the key question?

- In aging populations, are there ethnic differences in respiratory impairment?

What is the bottom line?

- Lambda-mu-sigma (LMS)-calculated spirometric $Z$ scores rigorously account for age-related changes in lung function. Recently, the Global Lung Function Initiative (GLI) expanded the availability of LMS spirometric Z scores to multiple ethnicities. Hence, in aging populations, the GLI provides an opportunity to rigorously evaluate ethnic differences in respiratory impairment, including spirometric airflow limitation and restrictive pattern.

\section{Why read on?}

- In a large sample of people aged 40-80, we found ethnic differences in GLI-defined respiratory impairment, including prevalence rates and associations with health outcomes. In particular, African Americans present a unique public health challenge, with high rates of respiratory impairment being associated with increased mortality but not respiratory symptoms.
\end{abstract} with respiratory symptoms but only in white Americans and Mexican Americans-aOR 2.16 (1.51 to 3.07) and 2.12 (1.45 to 3.08 ), respectively.

Conclusions In an aging population, we found ethnic differences in GLI-defined respiratory impairment. In particular, African Americans had high rates of respiratory impairment that were associated with mortality but not respiratory symptoms.

\section{INTRODUCTION}

Prior work suggests that ethnic differences exist in respiratory disease. ${ }^{1-3}$ For example, as reported by the Centers for Disease Control and Prevention (USA), prevalence rates for chronic bronchitis and emphysema are higher in white Americans than in African Americans or Hispanics. ${ }^{1} 2$ Similarly, age-adjusted death rates for chronic obstructive pulmonary disease (COPD), defined as chronic bronchitis or emphysema, are higher in white Americans than in African Americans or Hispanics. ${ }^{13}$ These epidemiologic data have limitations, however, for at least two reasons. ${ }^{1-7}$ First, confirmation of airway obstruction as a criterion for diagnosing COPD is underutilised in clinical practice-that is, chronic bronchitis and emphysema may occur in the absence of airway obstruction and vice versa. ${ }^{4} 57$ Second, death certificates in patients with respiratory disease may misclassify the cause of death. ${ }^{6}$

Spirometry provides an objective evaluation of respiratory disease, including potential ethnic differences. ${ }^{8} 9$ In particular, respiratory disease is often established by a reduction in spirometric function, heretofore termed a respiratory impairment, and is subsequently categorised as airflow limitation (airway obstruction) or restrictive pattern. ${ }^{3} 910$ Importantly, because respiratory disease occurs more frequently in aging populations ( $\geq 40$ years), ${ }^{12}$ the spirometric criteria that establish respiratory impairment must account for age-related reductions in lung function and the age-related variability in spirometric performance. ${ }^{9-18}$

The lambda-mu-sigma (LMS) method rigorously accounts for age-related changes in lung function by using Z-scores that incorporate the mean $(\mathrm{mu})$ representing how spirometric measures change based on predictor variables (age and height); the coefficient of variation (sigma) - representing the spread of reference values; and skewness (lambda)- 
representing departure from normality. ${ }^{11}{ }^{12} \mathrm{~A} Z \mathrm{Z}$ score of -1.64 defines the lower limit of normal (LLN) as the fifth percentile of the distribution. ${ }^{11}{ }^{12}$ Notably, using data from large reference populations of asymptomatic lifelong non-smokers, the Global Lung Function Initiative (GLI) has recently published equations that expand the availability of LMS-calculated spirometric $\mathrm{Z}$ scores, allowing respiratory impairment to be established across multiple ethnicities (see Methods). ${ }^{12}$

Whether ethnic differences exist in GLI-defined respiratory impairment has not yet been evaluated. Therefore, using GLI-based spirometric criteria and data from the Third National Health and Nutrition Examination Survey (NHANES III) ${ }^{19}$ including participants aged $40-80$ who were specifically identified as white Americans, African Americans and Mexican Americanswe calculated prevalence rates for airflow limitation and restrictive pattern, and their corresponding associations with 5-year all-cause mortality and respiratory symptoms. As a secondary aim, we also evaluated sex and smoking history as potential effect modifiers of the associations of interest. The results of the present study may inform public health policy and clinical practice regarding ethnic differences in respiratory impairment.

\section{METHODS}

\section{Study population}

NHANES III is a national probability sample of Americans aged 8-80, assembled in 1988-1994, with white Americans, African Americans and Mexican Americans representing the three largest ethnic groups. A separate Hispanic category was also identified but comprised only $2.4 \%$ of the NHANES III cohort. ${ }^{19}$ Given our specific aims, our analytical sample therefore included participants aged 40-80 who were white Americans, African Americans or Mexican Americans and who, at baseline, had no self-reported asthma and had completed at least two American Thoracic Society (ATS) acceptable spirometric manoeuvres (the maximal exhalation manoeuvre continued for at least $6 \mathrm{~s}$, with a minimum $2 \mathrm{~s}$ terminal plateau). ${ }^{19} \mathrm{We}$ selected age $\geq 40$ because respiratory impairment and its related mortality are unusual in younger people. ${ }^{13}$ We excluded participants who had self-reported asthma to focus on COPD as the cause of airflow limitation (see online supplementary appendix table A1, regarding frequency distributions of self-reported asthma, stratified by ethnicity and spirometric categories).

The institutional review boards from the Veterans Affairs Connecticut Healthcare System and Yale University approved the study, granting exemption from participant consent because it involved de-identified data that were publicly available.

\section{Clinical measures}

NHANES III recorded all-cause mortality, ascertained from a public use linked mortality file that contained information based on the National Death Index. ${ }^{20}$ For the present study, mortality surveillance occurred over 5 years.

NHANES III also recorded respiratory symptoms at the baseline visit, including chronic bronchitis, wheezing and dyspnoea. Specifically, participants were classified as having respiratory symptoms if they answered 'yes' to any of the following four questions ${ }^{19}$ : 'Do you usually cough on most days for three consecutive months or more during the year?'; 'Do you bring up phlegm on most days for three consecutive months or more during the year?'; 'Have you had wheezing or whistling in your chest at any time in the past 12 months?'; or 'Are you troubled by shortness of breath when hurrying on level ground or walking up a slight hill?'.
Other clinical data included age, sex, height, body mass index (BMI), ethnicity, health status, chronic conditions and smoking history. ${ }^{21}$ Reduced health status was defined as a self-reported rating of 'fair-to-poor'. Chronic conditions included selfreported, physician-diagnosed hypertension, COPD, diabetes, stroke, myocardial infarction and heart failure. For a smoking history to be established, $\geq 10$ pack-years of cigarette consumption was required. Participants were also classified as having high cardiovascular $(\mathrm{CV})$ risk based on $\mathrm{BMI} \geq 30$ or having a history of hypertension, diabetes, stroke, myocardial infarction or heart failure.

\section{Spirometry}

At the baseline visit, spirometry was performed using ATS protocols. ${ }^{19} 21$ The measures of interest included the forced vital capacity (FVC) and forced expiratory volume in $1 \mathrm{~s}\left(\mathrm{FEV}_{1}\right)$. Using the largest set of $\mathrm{FEV}_{1}$ and $\mathrm{FVC}$ values that were recorded in any of the ATS-acceptable spirometric manoeuvres, the $\mathrm{FEV}_{1} / \mathrm{FVC}$ was also calculated. ${ }^{8} \quad{ }^{19} 21$ These spirometric measures were then expressed as $\mathrm{Z}$ scores, using the GLI equations. $^{12}$

As per recommendations from the ATS and European Respiratory Society, the diagnostic threshold for spirometric measures was set at the fifth percentile of distribution, defining the LLN. ${ }^{9}$ In addition, because a substantial proportion of participants had risk factors for respiratory impairment, including smoking history, respiratory symptoms, and high cardiovascular risk, the LLN at the $5^{\text {th }}$ percentile was also deemed more clinically appropriate than the $2.5^{\text {th }}$ percentile, which is otherwise recommended for screening only. ${ }^{9} 1112$ In the present study, the LLN was thus defined by a $Z$ score of -1.64 , corresponding to the fifth percentile of the distribution of $Z$ scores. ${ }^{10-18}$ The respiratory status of each participant was then categorised as normal spirometry $\left(\mathrm{FEV}_{1} / \mathrm{FVC}\right.$ and $\mathrm{FVC}$, both $\left.\geq \mathrm{LLN}\right)$ or respiratory impairment, including airflow limitation $\left(\mathrm{FEV}_{1} / \mathrm{FVC}\right.$ $<\mathrm{LLN})$ or restrictive pattern $\left(\mathrm{FEV}_{1} / \mathrm{FVC} \geq \mathrm{LLN}\right.$ but $\left.\mathrm{FVC}<\mathrm{LLN}\right)$.

\section{Statistical analysis}

Baseline characteristics and the frequency distributions of respiratory impairment, respiratory symptoms and death were first summarised as means and SEs, or as counts and percentages. Ethnic differences were compared using the Rao-Scott $\chi^{2}$ test for categorical variables and least squares regression for continuous variables. $\mathrm{p}$ Values were adjusted for multiple comparisons using the false discovery rate procedure. ${ }^{22}$

The association between respiratory impairment and death was then evaluated using Cox regression models. The following covariates, identified a priori as clinically plausible confounders, were entered into the adjusted model (regardless of their level of statistical significance): age, sex, smoking history, high CV risk and reduced health status. Airflow limitation and restrictive pattern were treated as nominal categories, with the reference group including participants who had normal spirometry. Each model's goodness of fit was assessed by model-fitting procedures and by the analysis of residuals. The proportional hazards assumption was tested by using interaction terms for the time-to-event outcome and each variable in the multivariable model; the terms were retained if $\mathrm{p}<0.05$ after adjusting for the multiplicity of comparisons. Higher-order effects were tested for the continuous covariates and included in the final model if they met a forward selection criterion of $\mathrm{p}<0.20$.

Similarly, the association between respiratory impairment and respiratory symptoms at baseline was evaluated by calculating 
Table 1 Baseline characteristics according to ethnicity

\begin{tabular}{|c|c|c|c|c|c|c|}
\hline \multirow[b]{2}{*}{ Characteristic } & \multirow{2}{*}{$\begin{array}{l}\text { White Americans } \\
\mathrm{N}=3506\end{array}$} & \multirow{2}{*}{$\begin{array}{l}\text { African Americans } \\
\mathrm{N}=1860\end{array}$} & \multirow{2}{*}{$\begin{array}{l}\text { Mexican Americans } \\
\mathrm{N}=1749\end{array}$} & \multicolumn{3}{|c|}{ Adjusted $p$ value } \\
\hline & & & & W vs $A$ & W vs $M$ & A vs $M$ \\
\hline Age (years), mean (SE) & $60.7(0.4)$ & $56.0(0.5)$ & $56.0(0.4)$ & $<0.001$ & $<0.001$ & 0.923 \\
\hline Women, $\mathrm{n}(\%)$ & $1830(52.2)$ & $968(52.0)$ & $847(48.4)$ & 0.923 & 0.101 & 0.066 \\
\hline BMI $\left(\mathrm{kg} / \mathrm{m}^{2}\right)$, mean (SE) & $27.2(0.1)$ & $28.5(0.2)$ & $28.6(0.2)$ & $<0.001$ & $<0.001$ & 0.905 \\
\hline $\mathrm{BMI} \geq 30, \mathrm{n}(\%)$ & $878(25.0)$ & $636(34.2)$ & $589(33.9)$ & $<0.001$ & $<0.001$ & 0.905 \\
\hline \multicolumn{7}{|l|}{ Smoking history, n (\%) } \\
\hline$<10$ pack-years & $1950(56.1)$ & $1183(64.9)$ & $1265(73.2)$ & $<0.001$ & $<0.001$ & $<0.001$ \\
\hline$\geq 10$ pack-years & $1524(43.9)$ & $641(35.1)$ & $462(26.8)$ & & & \\
\hline \multicolumn{7}{|l|}{ Chronic conditions, $\mathrm{n}(\%)^{*}$} \\
\hline Hypertension & 1279 (36.5) & $859(46.3)$ & $530(30.5)$ & $<0.001$ & 0.003 & $<0.001$ \\
\hline COPD & $319(9.1)$ & $93(5.0)$ & $66(3.8)$ & $<0.001$ & $<0.001$ & 0.139 \\
\hline Diabetes mellitus & $299(8.5)$ & $246(13.2)$ & $312(17.8)$ & $<0.001$ & $<0.001$ & $<0.001$ \\
\hline Myocardial infarction & $265(7.6)$ & $96(5.2)$ & $79(4.7)$ & 0.002 & 0.001 & 0.506 \\
\hline Stroke & $134(3.8)$ & $80(4.3)$ & $44(2.5)$ & 0.430 & 0.014 & 0.004 \\
\hline Heart failure & $127(3.6)$ & $89(4.8)$ & $105(6.0)$ & 0.065 & $<0.001$ & 0.165 \\
\hline High CV risk, n (\%)‡ & 1885 (53.8) & $1233(66.3)$ & $1021(58.4)$ & $<0.001$ & 0.020 & $<0.001$ \\
\hline Reduced health status, $\mathrm{n}(\%)$ & $672(19.2)$ & $609(32.8)$ & $731(41.8)$ & $<0.001$ & $<0.001$ & $<0.001$ \\
\hline
\end{tabular}

*Self-reported, physician diagnosed.

tIncluded chronic bronchitis or emphysema.

FIncluded the presence of any of the following: $\mathrm{BMI}>30$, hypertension, diabetes, heart failure, stroke or myocardial infarction.

A, African Americans; BMl, body mass index (weight in kg divided by height in $\mathrm{m}^{2}$ ); COPD, chronic obstructive pulmonary disease; CV, cardiovascular; M, Mexican Americans; W, white Americans.

ORs, using logistic regression models. Covariates in the adjusted model were as described previously.

Lastly, potential effect modifiers of associations with health outcomes were assessed. In these analyses, interactions for each ethnic group were evaluated and involved 'crossing' sex and smoking history, with airflow limitation and restrictive pattern. HRs for death and ORs for respiratory symptoms were estimated according to sex and smoking history, using separate regression models for each ethnic group and combinations of effect modifiers. In tests of potential effect modification, $p$ values for interaction terms were not adjusted for the multiplicity of comparisons, because the clinical interest was toward avoiding type II errors, rather than type I errors. Covariates included age, sex, smoking history, high CV risk and reduced health status, without the variable that was the effect modifier of interest.

SAS V.9.3 software (SAS Institute Inc 2011; Cary, North Carolina, USA) was used in the analyses, with a $\mathrm{p}<0.05$ (two sided) denoting statistical significance. The analyses accounted for the complex study design to obtain accurate SEs, but did not use sampling weights because post hoc deletions were made to the national NHANES III probability sample.

\section{RESULTS}

Table 1 summarises baseline characteristics according to ethnicity. Significant differences were as follows: white Americans were older and had the highest rates of having a smoking history and (self-reported, physician-diagnosed) COPD or myocardial infarction, but the lowest rates of obesity $(\mathrm{BMI} \geq 30)$ and reduced health status. African Americans had the highest rate of $\mathrm{CV}$ risk, including hypertension. Mexican Americans had the highest rates of diabetes and reduced health status, but the lowest rates of having a smoking history, hypertension or stroke.

Table 2 summarises respiratory impairment, respiratory symptoms and mortality according to ethnicity. Overall, the prevalence of airflow limitation varied in a progression of white

Table 2 Spirometry and health outcomes according to ethnicity

\begin{tabular}{|c|c|c|c|c|c|c|c|c|c|}
\hline \multirow[b]{2}{*}{ Characteristic } & \multicolumn{2}{|c|}{ White Americans $N=3506$} & \multicolumn{2}{|c|}{ African Americans $\mathrm{N}=1860$} & \multicolumn{2}{|c|}{$\begin{array}{l}\text { Mexican Americans } \\
\mathrm{N}=1749\end{array}$} & \multicolumn{3}{|c|}{ Adjusted $p$ value } \\
\hline & $\mathbf{n}$ & $\%(95 \% \mathrm{Cl})$ & $\mathbf{n}$ & $\%(95 \% \mathrm{Cl})$ & $\mathrm{n}$ & $\%(95 \% \mathrm{Cl})$ & W vs $A$ & W vs $M$ & A vs $M$ \\
\hline \multicolumn{10}{|l|}{ Spirometry* } \\
\hline Normal & 2778 & 79.3 (77.8 to 80.7 ) & 1482 & 79.7 (77.7 to 81.7) & 1504 & 86.0 (84.3 to 87.8 ) & 0.780 & $<0.001$ & $<0.001$ \\
\hline Airflow limitation & 531 & 15.1 (13.9 to 16.4$)$ & 230 & $12.4(10.7$ to 14.0$)$ & 144 & 8.2 (6.7 to 9.8 ) & 0.014 & $<0.001$ & 0.002 \\
\hline Restrictive pattern & 196 & 5.6 (4.6 to 6.5$)$ & 148 & $8.0(6.9$ to 9.0$)$ & 100 & 5.7 (4.5 to 6.9 ) & 0.002 & 0.863 & 0.016 \\
\hline \multicolumn{10}{|l|}{ Health outcomes } \\
\hline Respiratory symptomst & 1452 & 41.5 (39.2 to 43.8$)$ & 668 & 36.0 (33.5 to 38.5 ) & 604 & 34.6 (31.9 to 37.3 ) & $<0.001$ & $<0.001$ & 0.541 \\
\hline Deaths, n (\%)‡ & 308 & $8.8(7.6$ to 10.0$)$ & 173 & 9.3 (8.0 to 10.6 ) & 121 & 6.9 (5.4 to 8.4$)$ & 0.632 & 0.063 & 0.039 \\
\hline
\end{tabular}


Table 3 HRs for 5-year mortality, according to spirometric category and stratified by ethnicity*

\begin{tabular}{|c|c|c|c|c|c|c|}
\hline \multirow[b]{3}{*}{ Spirometric category† } & \multirow{2}{*}{\multicolumn{2}{|c|}{$\begin{array}{l}\text { White Americans } \\
\mathrm{N}=3467 \\
\text { HRs for } 5 \text {-year mortality }(95 \% \mathrm{Cl}) \neq \S\end{array}$}} & \multicolumn{2}{|l|}{$\begin{array}{l}\text { African Americans } \\
\mathrm{N}=1821\end{array}$} & \multicolumn{2}{|l|}{$\begin{array}{l}\text { Mexican Americans } \\
\mathrm{N}=1717\end{array}$} \\
\hline & & & \multirow[b]{2}{*}{ Unadjusted } & \multirow[b]{2}{*}{ Adjusted } & \multirow[b]{2}{*}{ Unadjusted } & \multirow[b]{2}{*}{ Adjusted } \\
\hline & Unadjusted & Adjusted & & & & \\
\hline Normal & 1.00 & & & & & \\
\hline Airflow limitation & 2.31 (1.75 to 3.06$)$ & $1.66(1.23$ to 2.25$)$ & 2.58 (1.91 to 3.50$)$ & 1.60 (1.09 to 2.36$)$ & 2.18 (1.39 to 3.40$)$ & 1.80 (1.17 to 2.76$)$ \\
\hline Restrictive pattern & $3.10(2.30$ to 4.17$)$ & 2.56 (1.84 to 3.55$)$ & 2.91 (1.88 to 4.50$)$ & 3.23 (2.06 to 5.05$)$ & $2.88(1.34$ to 6.21$)$ & $2.09(0.89$ to 4.90$)$ \\
\hline \multicolumn{7}{|c|}{ 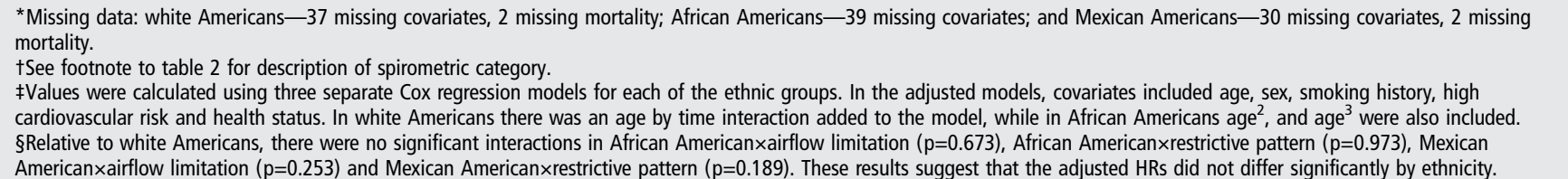 } \\
\hline
\end{tabular}

Americans $>$ African Americans $>$ Mexican Americans, whereas restrictive pattern varied in a progression of African Americans $>$ Mexican Americans and White Americans. Whereas airflow limitation exceeded the $5 \%$ prevalence level that is expected for a normal population (using our LLN threshold) across the three ethnicities, restrictive pattern exceeded the $5 \%$ prevalence level only in African Americans. The frequency of respiratory symptoms varied in a progression of White Americans $>$ African Americans and Mexican Americans. The frequency of deaths over 5 years varied in a progression of African Americans and White Americans>Mexican Americans.

Table 3 shows adjusted HRs (aHRs) for death, according to spirometric category and ethnicity. Relative to normal spirometry, airflow limitation was associated with mortality in white Americans, African Americans and Mexican Americans-aHR 1.66 (1.23 to 2.25$), 1.60$ (1.09 to 2.36) and 1.80 (1.17 to 2.76), respectively. Restrictive pattern was associated with mortality in white Americans and African Americans-aHR 2.56 (1.84 to 3.55 ) and 3.23 (2.06 to 5.05), respectively. Mexican Americans also had an increased aHR but this was not statistically significant-aHR 2.09 (0.89 to 4.90). In these analyses of mortality, there were no significant interactions between respiratory impairment and ethnicity (ie, HRs were similar).

Table 4 shows adjusted ORs (aORs) for respiratory symptoms, according to spirometric category and ethnicity. Relative to normal spirometry, airflow limitation was associated with respiratory symptoms in white Americans, but had only borderline statistical significance in African Americans and was not associated in Mexican Americans-aOR 2.15 (1.70 to 2.73),
1.38 (0.99 to 1.92$)$ and $1.26(0.90$ to 1.76$)$, respectively. Restrictive pattern was associated with respiratory symptoms in white Americans and Mexican Americans but not African Americans-aOR 2.16 (1.51 to 3.07), 2.12 (1.45 to 3.08) and $1.08(0.70$ to 1.67$)$, respectively. In these analyses of respiratory symptoms, there were significant interactions between respiratory impairment and ethnicity, with African Americans in particular having weak to no associations (ie, ORs were significantly lower, relative to white Americans).

Effect modification by sex and smoking history of the association between respiratory impairment and mortality were not significant (data not shown). In contrast, and as shown in figures 1 and 2, the aOR for respiratory symptoms was significantly modified in several situations: sex, among African Americans who had airflow limitation-aOR $0.86 \quad 0.55$ to 1.34 ) and 1.93 (1.18 to 3.17 ) for women and men, respectively $(\mathrm{p}=0.010)$, and among African Americans who had restrictive pattern-aOR 0.83 (0.53 to 1.31) and 1.66 (0.90 to 3.07) for women and men, respectively $(p=0.024)$; and (2) smoking history, among white Americans who had airflow limitationaOR 1.48 (0.96 to 2.30) and 2.57 (1.94 to 3.41) for < and $\geq 10$ pack-years, respectively $(\mathrm{p}=0.025)$.

\section{DISCUSSION}

In a large sample of people aged 40-80, we found that GLI-defined respiratory impairment differed in the following: prevalence: airflow limitation was more common in white Americans and African Americans than Mexican Americans, while restrictive pattern was more common in African

Table 4 ORs for respiratory symptoms, according to spirometric category and stratified by ethnicity*

\begin{tabular}{|c|c|c|c|c|c|c|}
\hline \multirow[b]{3}{*}{ Spirometric category $†$} & \multicolumn{2}{|l|}{$\begin{array}{l}\text { White Americans } \\
\mathrm{N}=3465\end{array}$} & \multicolumn{2}{|l|}{$\begin{array}{l}\text { African Americans } \\
\mathrm{N}=1821\end{array}$} & \multicolumn{2}{|l|}{$\begin{array}{l}\text { Mexican Americans } \\
\mathrm{N}=1716\end{array}$} \\
\hline & \multicolumn{6}{|c|}{ ORs for respiratory symptoms $(95 \% \mathrm{CI}) \ddagger \S$} \\
\hline & Unadjusted & Adjusted & Unadjusted & Adjusted & Unadjusted & Adjusted \\
\hline Normal & 1.00 & & & & & \\
\hline Airflow limitation & $2.70(2.20$ to 3.32$)$ & $2.15(1.70$ to 2.73$)$ & 1.41 (1.02 to 1.94$)$ & $1.38(0.99$ to 1.92$) \S$ & 1.25 (0.90 to 1.72$)$ & $1.26(0.90$ to 1.76$) \S$ \\
\hline Restrictive pattern & 2.67 (1.90 to 3.76$)$ & 2.16 (1.51 to 3.07$)$ & 1.41 (0.96 to 2.08$)$ & $1.08(0.70$ to 1.67$) \S$ & 2.60 (1.92 to 3.52$)$ & $2.12(1.45$ to 3.08$)$ \\
\hline
\end{tabular}



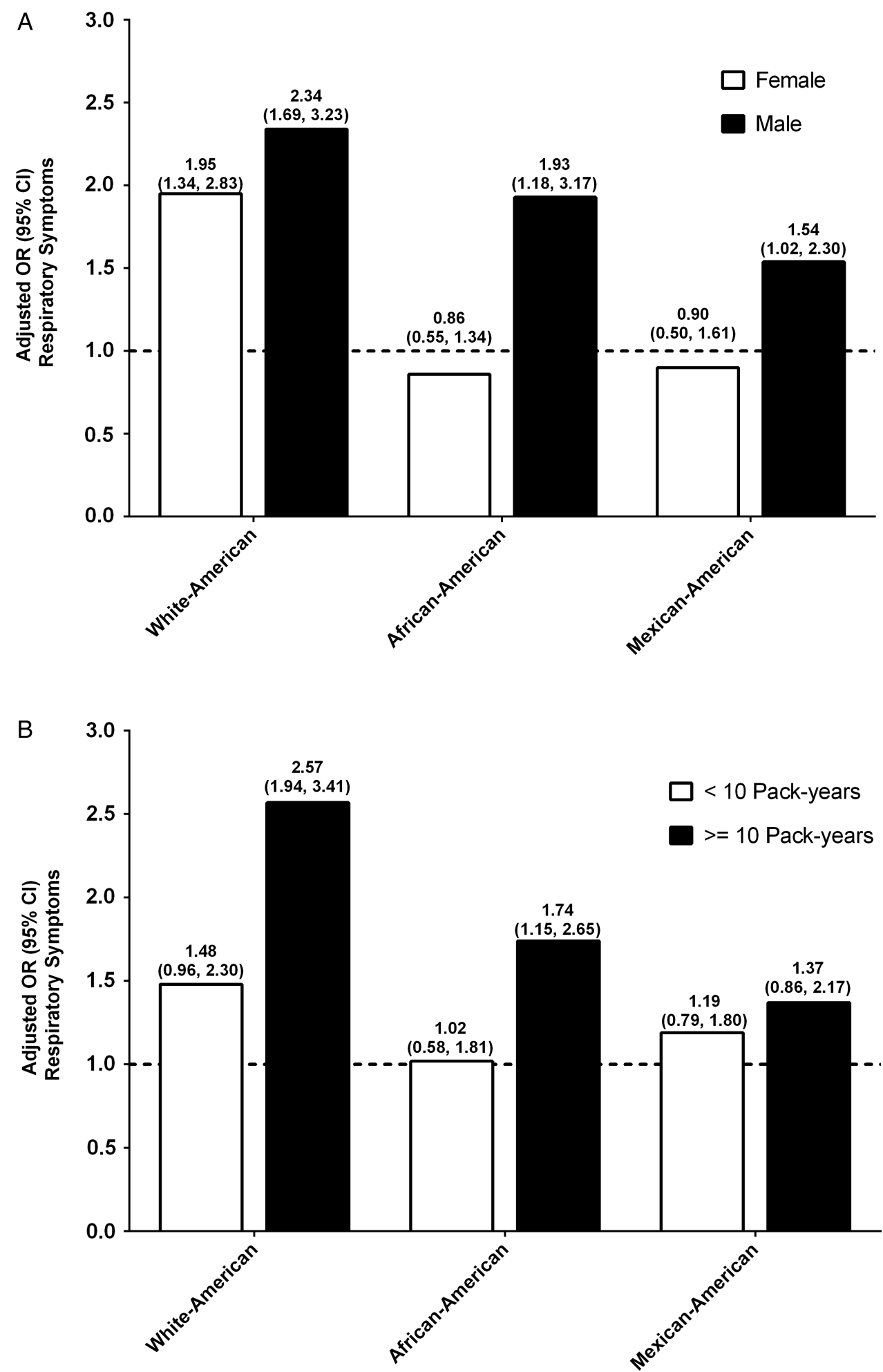

Figure 1 Adjusted OR $(95 \% \mathrm{Cl})$ for respiratory symptoms among participants who had airflow limitation, stratified by effect modifier-sex (A) and smoking history (B). Separate logistic regression models were used for each ethnic group and effect modifier combination, with normal spirometry as the reference group. Covariates included age, sex, smoking history, high CV risk and reduced health status, without the variable that was the effect modifier of interest. (A) Airflow limitation $\times$ sex (significant interaction in African Americans, $p=0.010$ ). (B) Airflow limitation $\times$ smoking history (significant interaction in white Americans, $\mathrm{p}=0.025)$. CV, cardiovascular.

Americans than white Americans or Mexican Americans; (2) allcause mortality: airflow limitation was associated with mortality in all three ethnic groups, while restrictive pattern was associated with mortality only in white Americans and African Americans-furthermore, the magnitude of these associations did not differ by ethnicity; respiratory symptoms: airflow limitation was associated with respiratory symptoms but only in white Americans, while restrictive pattern was associated with respiratory symptoms but only in white Americans and Mexican Americans-furthermore, the magnitude of these associations 

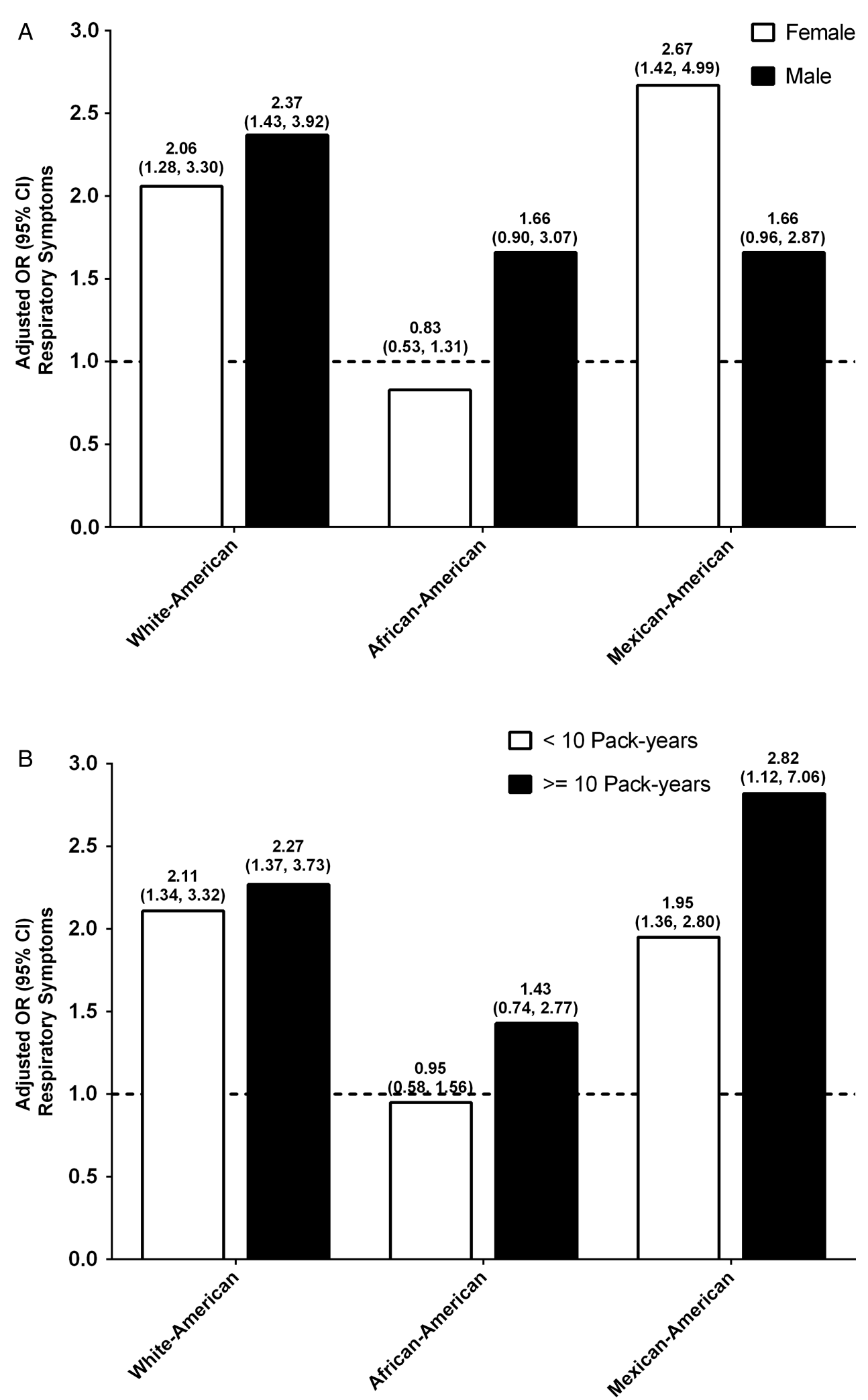

Figure 2 Adjusted OR $(95 \% \mathrm{Cl})$ for respiratory symptoms among participants who had restrictive pattern, stratified by effect modifier-sex (A) and smoking history (B). Separate logistic regression models were used for each ethnic group and effect modifier combination, with normal spirometry as the reference group. Covariates included age, sex, smoking history, high CV risk, and reduced health status, without the variable that was the effect modifier of interest. (A) Restrictive pattern $\times$ sex (significant interaction in African Americans, $p=0.024)$. (B) Restrictive pattern $\times$ smoking history (no significant interaction). CV, cardiovascular.

differed by ethnicity, with African Americans in particular having weak to no associations; and effect modification: female sex decreased the association of airflow limitation and restrictive pattern with respiratory symptoms but only in African Americans, while smoking history increased the association of airflow limitation with respiratory symptoms but only in white 
Americans-otherwise, there was no effect modification for the mortality outcome.

These results indicate that ethnic differences exist in GLI-defined respiratory impairment, including prevalence rates, associations with health outcomes, and effect modification. In particular, African Americans present a unique public health challenge, with high rates of respiratory impairment being associated with mortality but not respiratory symptoms.

Our approach for evaluating ethnic differences in respiratory impairment has a strong mathematical and clinical rationale. As discussed earlier, GLI-defined respiratory impairment is based on LMS-calculated spirometric Z scores that rigorously account for age-related changes in lung function, including variability in spirometric performance and skewness of reference data. ${ }^{11} 12$ As additional evidence supporting this approach in clinical practice, $\mathrm{Z}$ scores are routinely used to diagnose osteoporosis (bone mineral density) and the LMS method is widely applied to construct growth charts. ${ }^{1123}$ In the current context, ethnic differences were also evaluated based on associations between respiratory impairment and health outcomes. All-cause mortality is a definitive outcome that is resistant to miscoding and has been the primary endpoint in clinical trials. ${ }^{24}$ Respiratory symptoms, including dyspnoea, chronic bronchitis and wheezing, are often the bases for pursuing healthcare. ${ }^{24-26}$

Because we excluded participants who had self-reported asthma, the spirometric diagnosis of airflow limitation in the present study was likely due to airway obstruction from COPD. Hence, our results suggest that white Americans and African Americans have significantly higher rates of spirometryconfirmed COPD than Mexican Americans (table 2). These higher rates may be due to a greater smoking exposure in white Americans and African Americans, along with a possible ethnicspecific protection in Mexican Americans. ${ }^{27}$

Because a reduced FVC is associated with the metabolic syndrome, coronary heart disease and sudden cardiac death, ${ }^{28-30}$ and because a reduced FVC is a required criterion for establishing restrictive pattern, ${ }^{9}$ we postulate that a $\mathrm{CV}$ mechanism may have been an important contributor to restrictive pattern in our study population, including its association with health outcomes. ${ }^{14} \quad 15 \quad 17 \quad 18$ This is especially relevant to African Americans. The latter group had the highest rates of CV risk and restrictive pattern, whereas white Americans and Mexican Americans had lower rates of $\mathrm{CV}$ risk and restrictive pattern (tables 1 and 2, respectively).

The present study also demonstrated a differential impact of ethnicity on associations with death and respiratory symptoms (tables 3 and 4, respectively). For example, in adjusted analyses, we found that white Americans who had airflow limitation or restrictive pattern had a significant increase in the risk of death and odds of having respiratory symptoms. In contrast, African Americans who had restrictive pattern had a significant increase in the risk of death but not in the odds of having respiratory symptoms. Similarly, Mexican Americans who had airflow limitation had a significant increase in the risk of death but not in the odds of having respiratory symptoms. Lastly, ethnic differences on associations with respiratory symptoms, but not death, were also seen regarding effect modification by female sex, being significant only in African Americans, and by smoking history, being significant only in white Americans (figures 1 and 2).

The differential impact of ethnicity on associations with respiratory symptoms may affect prevalence rates for respiratory disease. In particular, we found that the rate of airflow limitation (spirometry-confirmed COPD) relative to self-reported, physician- diagnosed COPD was higher in white Americans (15.1\% vs 9.1\%, respectively), yet more than doubled in African Americans (12.4\% vs $5.0 \%$, respectively) and Mexican Americans $(8.2 \%$ vs $3.8 \%$, respectively) (tables 1 and 2 ). We postulate that the lower rates of self-reported, physician-diagnosed COPD occurred because spirometry is not routinely applied in clinical practice, or participants may not have sought medical care, and because respiratory symptoms are neither sufficient nor necessary to establish clinically meaningful respiratory disease. ${ }^{5} 716$ Prior work by our own group has shown, for example, that $31 \%$ of participants who had moderate-to-severe spirometry-confirmed COPD (based on $\mathrm{FEV}_{1} \mathrm{Z}$ scores) had no respiratory symptoms. ${ }^{16}$ In addition, the designation of self-reported, physician-diagnosed COPD may have limited diagnostic accuracy. In the present study, more than half of the participants who had self-reported, physician-diagnosed COPD had normal spirometry (see online supplementary appendix table A2).

In light of the above discussion, future work should evaluate additional health outcomes, including other verbal descriptors of dyspnoea, measures of health-related quality of life, and exercise capacity (6 min walk test), across multiple ethnicities. ${ }^{31} 32$ Moreover, because preventive healthcare is available (smoking cessation, vaccinations, CV risk modification, and reduction of indoor and outdoor air pollutants), health outcomes should also be evaluated in people aged $\geq 40$ who at baseline have a spirometric respiratory impairment but no respiratory symptoms (as defined in the present study). ${ }^{31} 32$ The latter assessment has precedence, given that the Framingham Risk Score is currently recommended in all asymptomatic people aged $\geq 40$, including those without a clinical history of coronary heart disease. ${ }^{33}$

Although the present study used rigorous spirometric criteria, at least three potential limitations are noted. First, NHANES III does not provide sufficient data to confirm the pathophysiology of respiratory impairment. For example, in addition to COPD, airflow limitation could be due to asthma, given that spirometry in NHANES III was not specifically obtained after a bronchodilator, that self-reported asthma (a key exclusion criterion) may have been underreported by participants, and that longstanding asthma may lead to irreversible airflow limitation. ${ }^{34}$ Similarly, restrictive pattern as a basis for establishing pulmonary restriction requires confirmation by a reduced total lung capacity, and may have included several non-CV aetiologies. $9{ }^{10}$ Second, selfreported ethnicity may not be entirely accurate, potentially leading to misclassification in the ethnic-specific reference equations that were used to calculate spirometric $\mathrm{Z}$ scores. ${ }^{12}$ Moreover, because pulmonary function like many clinical phenomena occurs along a continuum, spirometric $\mathrm{Z}$ scores that are just above or below the LLN may have limited diagnostic accuracy when evaluating a respiratory impairment. A potential related limitation is that establishing the LLN at the 5th percentile, rather than the $2.5^{\text {th }}$ percentile (see methods), ${ }^{9}{ }^{11} 12$ may increase false-positive designations for respiratory impairment. Nonetheless, the $2.5^{\text {th }}$ percentile threshold may substantially increase false-negative designations, particularly given that NHANES III participants aged 40-80 frequently had a smoking history, respiratory symptoms and high cardiovascular risk. Third, there may be differences in cultural, geographical and socioeconomic factors between and within the three ethnic categories. ${ }^{35}$ In particular, differences in sedentary behaviour could alter the association between respiratory impairment and symptoms (exertional dyspnoea). To address these limitations, future studies should include comprehensive tests of cardiopulmonary function and an assessment of genetic, cultural, geographical and socioeconomic factors. 


\section{CONCLUSION}

In a large sample of people aged $40-80$, we found that significant ethnic differences existed in GLI-defined respiratory impairment, including prevalence rates, associations with health outcomes and the presence of effect modifiers. In particular, African Americans present a unique public health challenge, with high rates of airflow limitation and restrictive pattern being associated with increased mortality but not respiratory symptoms. These results may inform future research and public health policy regarding ethnic differences in respiratory impairment.

Contributors CAVF is guarantor of the study. CAVF, GM, TMG, JC, PHQ and PHVN contributed to the study conception and design. CAVF, GM, TMG, JC, PHQ and PHVN contributed to the interpretation and analysis of data. CAVF drafted the manuscript, and all authors revised the manuscript critically for important intellectual content and provided final approval of the version to be published.

Funding The study was conducted at the VA Clinical Epidemiology Research Center and the Yale Claude D Pepper Older Americans Independence Center (P30AG02134). CAVF is a recipient of a Career Development Award from the Department of Veterans Affairs and an R03 award from the National Institute on Aging (R03AG037051). TMG is the recipient of K24AG021507 and K07AG043587 from the National Institute on Aging. JC is supported by the Department of Veterans Affairs Cooperative Studies Program.

Competing interests None.

Ethics approval Institutional review boards from the Veterans Affairs Connecticut Healthcare System and Yale University (USA) approved the study.

Provenance and peer review Not commissioned; externally peer reviewed.

Data sharing statement The NHANES III dataset has been de-identified and is publicly available.

\section{REFERENCES}

1 Chronic Obstructive Pulmonary Disease. American Lung Association State of Lung Disease in Diverse Communities. 2010:35-40. http://www.lung.org/assets/ documents/publications/solddc-chapters/copd.pdf (accessed 3 May 2013).

2 Centers for Disease Control and Prevention. National Center for Health Statistics: National Health Interview Survey Raw Data, 2008. Analysis performed by American Lung Association Research and Program Services using SPSS and SUDAAN software.

3 Centers for Disease Control and Prevention. National Center for Health Statistics. CDC Wonder On-line Database, compiled from Compressed Mortality File 1999-2006 Series 20 No 2L. 2009

4 Miniati M, Monti S, Stolk J, et al. Value of chest radiography in phenotyping chronic obstructive pulmonary disease. Eur Respir J 2008:31:509-14.

5 Peto $\mathrm{R}$, Speizer $\mathrm{FE}$, Cochrane $\mathrm{AL}$, et al. The relevance in adults of airflow obstruction, but not of mucous hypersecretion, to mortality from chronic lung disease. Am Rev Respir Dis 1983;128:491-500.

6 Huiart L, Ernst P, Suissa S. Cardiovascular morbidity and mortality in COPD. Chest 2005; 128:2640-6.

7 Ferguson GT, Enright PL, Buist AS, et al. Office spirometry for lung health assessment in adults: a consensus statement from the National Lung Health Education Program. Chest 2000;117:1146-61.

8 Miller MR, Hankinson J, Brusasco V, et al. Standardisation of spirometry. Eur Respir J 2005:26:319-38.

9 Pellegrino $R$, Viegi $G$, Brusasco V, et al. Interpretative strategies for lung function tests. Eur Respir J 2005;26:948-68.

10 Vaz Fragoso CA, Gill T. Respiratory impairment and the aging lung: a novel paradigm for assessing pulmonary function. J Gerontol Med Sci 2012;67:264-75.

11 Stanojevic S, Wade A, Stocks J, et al. Reference ranges for spirometry across all ages. Am J Respir Crit Care Med 2008;177:253-60.
12 Quanjer PH, Stanojevic S, Cole TJ, et al. Multi-ethnic reference values for spirometry for the 3-95 year age range: the Global Lung Function 2012 equations. Eur Respir J 2012:40:1324-43.

13 Vaz Fragoso CA, Concato J, McAvay G, et al. The ratio of the forced expiratory volume in 1-second to forced vital capacity in establishing chronic obstructive pulmonary disease. Am J Respir Crit Care Med 2010;181:446-51.

14 Vaz Fragoso CA, Gill TM, McAvay G, et al. Evaluating respiratory impairment in middle-aged persons using lambda-mu-sigma derived Z-scores. Respir Care 2011;56:1771-7

15 Vaz Fragoso CA, Gill TM, McAvay G, et al. Respiratory impairment and mortality in older persons: a novel spirometric approach. J Investig Med 2011;59:1089-95.

16 Vaz Fragoso CA, Concato J, McAvay G, et al. Staging the severity of chronic obstructive pulmonary disease in older persons based on spirometric Z-scores. J Am Geriatr Soc 2011;59:1847-54.

17 Vaz Fragoso CA, Enright PL, McAvay G, et al. Frailty and respiratory impairment in older persons. Am J Med 2012;125:79-86.

18 Vaz Fragoso CA, Gill TM, McAvay G, et al. Respiratory impairment in older persons: when less means more. Am J Med 2013:126:49-57.

19 US Department of Health and Human Services. National Center for Health Statistics. Third National Health and Nutrition Examination Survey, 1988-94, NHANES III Laboratory Data File (CD-ROM), Public Use Data File Documentation Number 76200. Hyattsville, Maryland: Centers for Disease Control and Prevention, 1996. Available from National Technical Information Service, Springfield, Virginia.

20 Wheatcroft G, Cox CS, Lochner KA. Comparative analysis of the NHANES III public-use and restricted-use linked mortality files. Hyattsville, Maryland: National Center for Health Statistics, 2007. http://www.cdc.gov/nchs/data/datalinkage/h3_ mort_compare_2007_final.pdf

21 American Thoracic Society. Lung function testing: selection of reference values and interpretative strategies. American Thoracic Society. Am Rev Respir Dis 1991;144:1202-18.

22 Benjamini $Y$, Hochberg $Y$. Controlling the false discovery rate: a practical and powerful approach to multiple testing. J R Stat Soc Series B 1995;51:289-300.

23 Cummings SR, Bates D, Black DM. Clinical use of bone densitometry: scientific review. JAMA 2002;288:1889-97.

24 Gross NJ. Chronic obstructive pulmonary disease outcome measurements. Proc Am Thorac Soc 2005:2:267-71.

25 Cherry DK, Burt CW, Woodwell DA. National ambulatory medical care survey: 1999 summary. Adv Data Vital Health Stat 2001;322:1-36.

26 Qaseem A, Snow V, Shekelle $P$, et al. Diagnosis and management of stable chronic obstructive pulmonary disease: a clinical practice guideline from the American College of Physicians. Ann Intern Med 2007;147:633-8.

27 Bruse S, Sood A, Petersen $H$, et al. New Mexican Hispanic smokers have lower odds of chronic obstructive pulmonary disease and less decline in lung function than non-Hispanic whites. Am J Respir Crit Care Med 2011;184:1254-60.

28 Friedman GD, Klatsky AL, Siegelaub AB. Lung function and risk of myocardial infarction and sudden cardiac death. NEJM 1976;294:1071-5.

29 Lee HM, Le H, Lee BT, et al. Forced vital capacity paired with Framingham risk score for prediction of all-cause mortality. Eur Respir J 2010;36:1002-6.

30 Nakajima K, Kubouchi Y, Muneyuki T, et al. A possible association between suspected restrictive pattern as assessed by ordinary pulmonary function test and the metabolic syndrome. Chest 2008;134:712-18.

31 Parshall MB, Schwartzstein RM, Adams L, et al. An official American Thoracic Society statement: update on the mechanisms, assessment, and management of dyspnea. Am J Respir Crit Care Med 2012;185:435-52.

32 Han MK, Curran-Everett D, Dransfield MT, et al. Racial differences in quality of life in patients with COPD. Chest 2011;140:1169-76.

33 Greenland P, Alpert JS, Beller GA, et al. 2010 ACCF/AHA guideline for assessment of cardiovascular risk in asymptomatic adults. J Am Coll Cardiol 2010;56:e50-103.

34 Behrendt CE. Mild and moderate-to-severe COPD in nonsmokers: distinct demographic profiles. Chest 2005;128:1239-44.

35 Braun L, Wolfgang M, Dickersin K. Defining race/ethnicity and explaining difference in research studies on lung function. Eur Respir J 2013;41:1362-70. doi:10.1183/ 09031936.0009161 